\title{
Wind tunnel comparison of four VAWT configurations to test load-limiting concept and CFD validation
}

\author{
Jan Wiśniewski, Krzysztof Rogowski, Konrad Gumowski, and Jacek Szumbarski \\ Institute of Aeronautics and Applied Mechanics, Warsaw University of Technology, \\ Warsaw, 00-665, Poland
}

Correspondence: Jan Wiśniewski (jhwisniewski@meil.pw.edu.pl)

Received: 31 January 2020 - Discussion started: 14 May 2020

Revised: 21 August 2020 - Accepted: 27 October 2020 - Published: 24 February 2021

\begin{abstract}
The article describes results of experimental wind tunnel testing of four different straight-bladed vertical axis wind turbine model configurations. The experiment tested a novel concept of vertically dividing and azimuthally shifting a turbine rotor into two parts with a specific uneven height division in order to limit cycle amplitudes and average cycle values of bending moments at the bottom of the turbine shaft to increase product lifetime, especially for industrial-scale turbines. Testing reduction effects of simultaneously including a vertical gap between turbine rotor levels, increasing shaft length but also reducing aerodynamic interaction between rotor levels, has also been performed. Experiment results have shown very significant decreases of bending moment cycle amplitudes and average cycle values, for a wide range of measured wind speeds, for dual-level turbine configurations as compared to a single-level turbine configuration. The vertical spacing between levels equal to a blade's single chord length has proven to be sufficient, on laboratory scale, to limit interaction between turbine levels in order to achieve optimal reductions of tested parameters through an operating cycle shift between two position-locked rotor levels during a turbine's expected lifetime. CFD validation of maintaining the effect on industrial scale has been conducted, confirming the initial conclusions.
\end{abstract}

\section{Introduction}

Vertical axis wind turbine (VAWT) blades, unlike horizontal axis wind turbine blades, work in a high range of angles of attack within each rotation cycle (Ahmadi-Balouaki et al., 2014). Resulting high amplitudes of bending moment values and high maximum moment values at the bottom of a wind turbine shaft in a rotation cycle (Galinos et al., 2016) are strong deterrents to development of economically feasible large-scale VAWTs. The proposed concept for limiting those factors focuses on separating the rotor vertically into two or more parts of different lengths, shifted azimuthally in such a way as to maximally reduce maximum moment values and amplitudes at the bottom of the rotor shaft in a rotation cycle. The tested case had two rotor levels - a longer one, closer to the bottom of the shaft and a shorter one further from the bottom of the shaft - in order to achieve comparable values of bending moments at the bottom of the rotor shaft from each rotor level. Additional spacing between ro- tor levels was also tested in order to limit interaction between separate rotor levels.

The topic of lift-based large-scale VAWTs, despite the aforementioned technological drawbacks - a solution to which can be seen tested below - has been met with resurfacing interest, due to their specific advantages. While factors related to the blade tip not moving faster relative to the rest of the blade, allowing for lower noise emissions (Iida et al., 2004), lower bird death rates and no ice block launching, in areas where the risk exists, as compared to horizontal axis wind turbines (HAWTs) are important advantages for certain siting conditions, the key factor that keeps drawing researchers to VAWTs is the high aerodynamic efficiency potential. A study by Simão Ferreira et al. (2014), comparing six different methods for assessing power coefficients $\left(C_{\mathrm{p}}\right)$ for a wide range of tip speed ratio and rotor solidity, has calculated large-scale VAWT $C_{\mathrm{p}}$ for advantageous configurations for each model to be between 0.54 and 0.6. Straight- 
bladed VAWTs specifically hold an additional advantage easier manufacturing of blades (Chinchilla et al., 2011) and lower blade weight and material use compared to VAWTs with spiraling blades.

Spiral-bladed wind turbines are described in the literature as having lowered amplitude changes of their aerodynamics (Guo et al., 2019) - specifically the time amplitude of the sum of force values affecting the entire rotor is much lower for a standard spiral VAWT compared to a straight-bladed VAWT - as presented visually within the Journal of Power and Technology (Scheurich et al., 2011). Another study gives this relationship an averaged numeric value - stating that by replacing straight blades with helical ones in a VAWT rotor, the total force fluctuation amplitude is reduced by about $50 \%$ (Marini et al., 2010). It is important to note that these available factors do not reflect directly towards a key parameter of this study - cycle amplitudes of bending moments at the bottom of the turbine shaft, proportional to element loading and therefore determined as a parameter directly influencing turbine shaft reliability, expected lifetime and necessary material use as per use in expected lifetime for cyclic loading curves. Typical designs of spiral-bladed VAWTs are not optimal in smoothing bending moments at the base of the turbine shaft - there is an effect, but as the upper sections have greater leverage than the lower ones the effect achieved cannot be perfect. The solution to this, described in patent application PCT/PL2020/000054 lies in a non-linear twist operating on a similar principle to the upper portion of the concept that is the target of the paper, the upper portion of the rotor being a specific different size than the lower portion. Finally, both structural concerns and increased weight of spiral blades make the technology very interesting on small to medium scales but less cost-efficient than the concept validated within this paper, on the scale referenced and above.

\section{Test case description}

The testing was conducted in the WUT Variable Turbulence Tunnel in the $2.5 \mathrm{~m}$ wide and $2 \mathrm{~m}$ tall environmental test section of the tunnel.

Shown in Fig. 1 the WUT Variable Turbulence Tunnel is a large-scale sub-sonic wind tunnel with two independent test sections allowing for testing in a range of speeds up to $100 \mathrm{~m} / \mathrm{s}$. Air flow is generated by a $250 \mathrm{~kW}$ engine. Figure 1 shows a part of the Warsaw University of Technology including a section of the environmental part of the tunnel.

The model itself was $1.5 \mathrm{~m}$ high in the two shortest configurations, with a $57.5 \mathrm{~cm}$ turbine rotor diameter. The model was created with the upper level capable of shifting, in order to enable testing of different configurations. A three-blade rotor design was chosen, in addition to CFD simulations by the authors. A comparative analysis by Parashivoiu shows them to have better structural reliability than dual-blade designs (Parashivoiu, 2002). The model used the NACA 0018

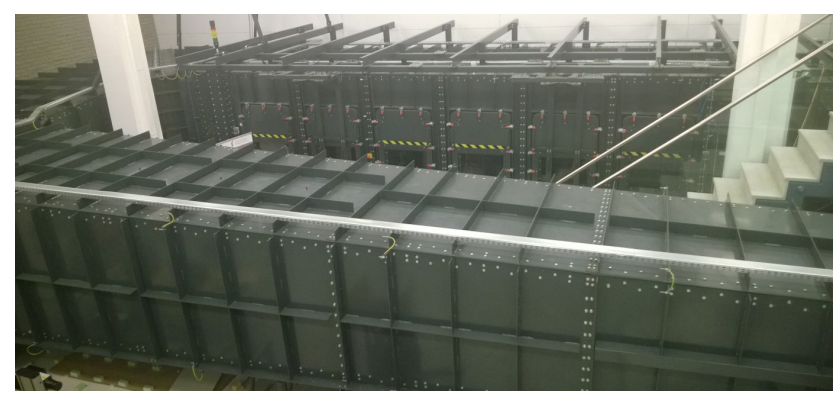

Figure 1. WUT Variable Turbulence Tunnel.

symmetrical airfoil, a classical VAWT airfoil used both in CFD-based studies (Rogowski et al., 2018) and experiments (Laneville and Vittecoq, 1986).

The concept tested has, in the presented version, two levels of blades within a rotor. The lower level is equipped with longer blades in order to provide similar maximum and minimum values of bending moment at the bottom of the turbine shaft as the higher level, only shifted in cycle by azimuthally displacing the upper and lower rotor level. In order to limit interference influencing the character of aerodynamic loading on each three-blade rotor level, variants with vertical spacing between rotor levels have also been tested - negatively influencing shaft length but decreasing aerodynamic interference between adjacent rotor levels. It is worthwhile to note that applying construction solutions reducing blade chord near the end of a rotor level (Islam et al., 2008) should result in lower spacing needs between adjacent turbine levels.

Figure 2 displays the four configurations used for final wind tunnel testing. Configuration $\mathrm{K}$ is a standard singlelevel VAWT with blade length equal to the sum of the length of both levels in other scenarios. Configuration A is a duallevel wind turbine, shifted azimuthally by $60^{\circ}$, with the second level starting at the exact height at which the first level ends. Configuration B is analogous to A, whereas there is a vertical gap between adjacent levels equal to a single chord length $(3.75 \mathrm{~cm})$. Configuration $\mathrm{C}$ has a vertical gap between levels equal to two chord lengths $(7.5 \mathrm{~cm})$.

The reason for conducting the tests was to measure the bending moment values at the bottom of the turbine tower for a laboratory-scale model of the authors' analyzed turbine concept, within a few configurations. The values were being measured for a range of inflow wind speeds between 4 and $12 \mathrm{~m} / \mathrm{s}$ while the turbine was rotating freely. Torque was not a measured parameter, as for the range of Reynolds numbers in the area of 10000 to 50000 within the experiment no airfoils are capable of providing characteristics comparable to ones for industrial-scale blades. Each measurement consisted of 10000 data acquisitions within the period of $10 \mathrm{~s}$. For many combinations of inflow wind speeds and geometry configurations, up to six measurements were taken to ensure that a momentary effect did not influence the results. To reduce noise within the measured signal, techniques from 


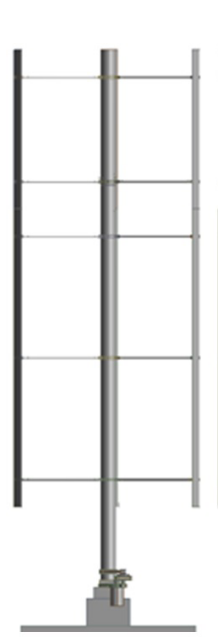

(k)

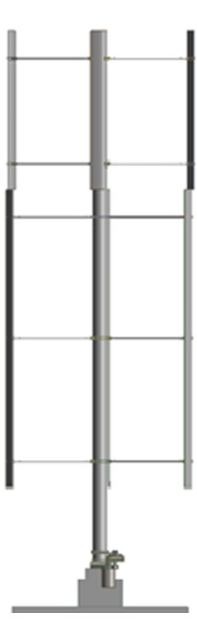

(a)

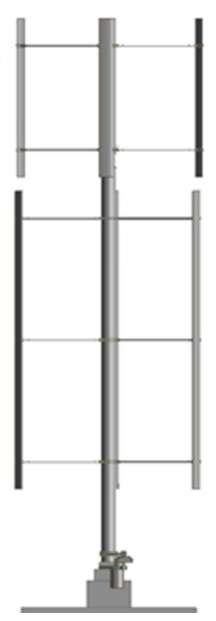

(b)

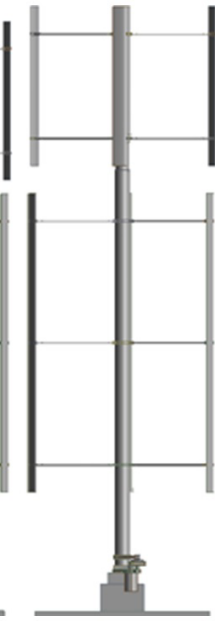

(c)
Figure 2. Chosen VAWT configurations tested in the wind tunnel.

exploratory data analysis (EDA) were used (Oerlemans and Migliore, 2004). Firstly a technique called hanning, or a running weighted mean, was implemented. Each data point was replaced with the sum of half the data point and one-fourth of the previous and next data points. This was used consecutively three times for better results, with 50-point median smoothing used twice afterwards for a final smoothened data set.

Figure 3 presents a 1 s sample of raw bending moment values recorded by the tensometric scale used in the experiment, as well as the refined bending moment values achieved by a five-step smoothing process used in order to eliminate signal noise. The data are from a measurement in configuration A, taken at the inflow wind speed of $11 \mathrm{~m} / \mathrm{s}$. The necessity of eliminating signal noise does, to a small extent, influence experiment results. The smoothing process, if done too subtly, maintains some artificial peak value increases. If the smoothing process is too major, it leads to filtering out peak values resulting from actual physical forces acting upon the rotor. Although the smoothing was done with care, it is important to remember that, especially for comparison of tens of cycles performed for four different geometries and a range of wind speeds, it introduces risk of slightly altering peak values. The smoothing process, while aiming to recreate the values without signal noise, may have some influence on the exact result values; however the possible scale of the effect is too small to have an impact on the general nature of the experiment results or conclusions on validating the potential effectiveness of the proposed solution.

\subsection{Configuration $\mathrm{K}$}

Table 1 shows results of measuring bending moments at the bottom of the turbine tower for a range of wind speeds between 4 and $12 \mathrm{~m} / \mathrm{s}$ for a freely rotating wind turbine in con-

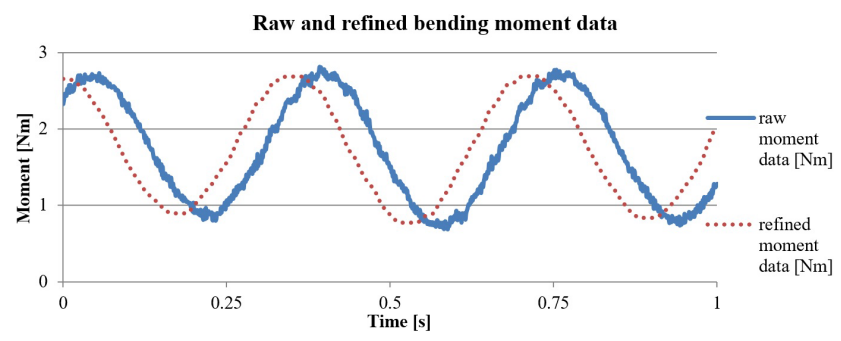

Figure 3. Sample of raw and refined bending data values from configuration A.

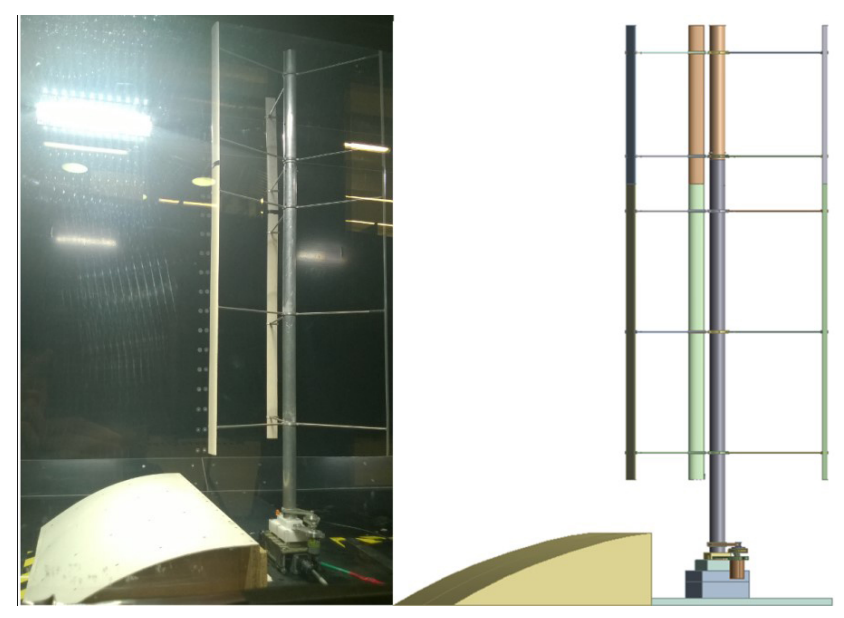

Figure 4. Model set in configuration K.

figuration $\mathrm{K}$. In general there is an increase in bending moment values and amplitudes, accompanying the growth of inflow wind speeds. The value increase, while not exactly proportional to the second power of the inflow speed, is strongly influenced by it, with two exceptions. It is noticeable from the values that, at 10 and $11 \mathrm{~m} / \mathrm{s}$, the turbine has started oscillating by bending. It is especially evident for $10 \mathrm{~m} / \mathrm{s}$ when the moment amplitude is several times larger than for many other measurements. It is also visible that for $10 \mathrm{~m} / \mathrm{s}$ the moment amplitude is noticeably higher than the moment peak values, meaning that for a part of the loading cycle the turbine is being pushed forward against the direction of the wind. That effect is, to a much smaller degree, visible at the inflow speed of $11 \mathrm{~m} / \mathrm{s}$.

Figure 4 displays the model set in configuration K. It shows a single-level turbine, with straight, prolonged blades.

\subsection{Configuration A}

Figure 5 displays the model set in configuration A. It shows a basic dual-level turbine, shifted azimuthally between levels by $60^{\circ}$. There is no vertical displacement between levels the upper level of the rotor starts at the same height the lower level ends. 
Table 1. Control case $\mathrm{K}$ testing parameters of bending moments for wind speed range.

\begin{tabular}{lrrrrrrrrr}
\hline Wind speed [m/s] & 4 & 5 & 6 & 7 & 8 & 9 & 10 & 11 & 12 \\
\hline Average moment amplitude [Nm] & 0.077 & 0.102 & 0.243 & 0.358 & 0.522 & 1.193 & 7.799 & 3.316 & 1.672 \\
Max moment amplitude [Nm] & 0.118 & 0.183 & 0.389 & 0.604 & 0.809 & 1.529 & 8.249 & 3.762 & 2.326 \\
Min moment amplitude [Nm] & 0.025 & 0.021 & 0.036 & 0.168 & 0.157 & 0.833 & 7.211 & 2.701 & 1.066 \\
Average peak value [Nm] & 0.254 & 0.413 & 0.643 & 0.886 & 1.221 & 1.817 & 5.647 & 3.505 & 3.047 \\
Max peak value [Nm] & 0.270 & 0.509 & 0.753 & 0.994 & 1.363 & 1.976 & 5.941 & 3.727 & 3.414 \\
\hline
\end{tabular}
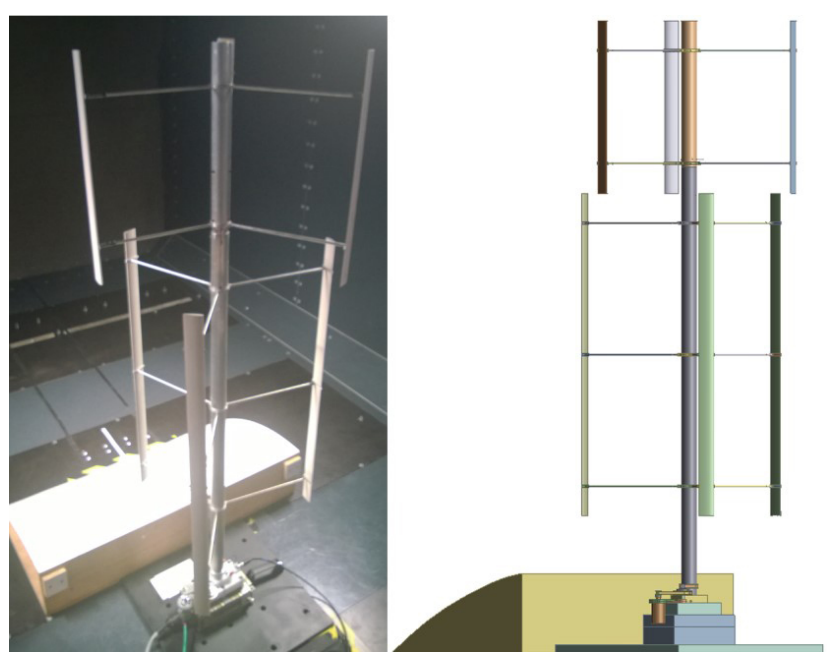

Figure 5. Model set in configuration A.

Table 2 shows results of measuring bending moments at the bottom of the turbine tower for a range of wind speeds between 4 and $12 \mathrm{~m} / \mathrm{s}$ for a freely rotating wind turbine in configuration A. In general there is an increase in bending moment values and amplitudes, accompanying the growth of inflow wind speeds. At the inflow speed of $11 \mathrm{~m} / \mathrm{s}$, the shape of the bending moment data curve and the fact that both moment amplitudes and peak values are greater than for $12 \mathrm{~m} / \mathrm{s}$ suggest that for $11 \mathrm{~m} / \mathrm{s}$ resonance occurs. The increase of values due to resonance is much smaller than in the single-level configuration $\mathrm{K}$.

\subsection{Configuration B}

Figure 6 displays the model set in configuration B. It shows a dual-level turbine, shifted azimuthally between levels by $60^{\circ}$. The height of the vertical gap between rotor levels is equal to $3.75 \mathrm{~cm}-$ one chord length.

Table 3 shows results of measuring bending moments at the bottom of the turbine tower for a range of wind speeds between 4 and $12 \mathrm{~m} / \mathrm{s}$ for a freely rotating wind turbine in configuration B. At the inflow speed of $11 \mathrm{~m} / \mathrm{s}$, the shape of the curve and the fact that both moment amplitudes and peak values are greater than for $12 \mathrm{~m} / \mathrm{s}$ suggest that for $11 \mathrm{~m} / \mathrm{s}$ resonance occurs. The growth of values due to resonance is

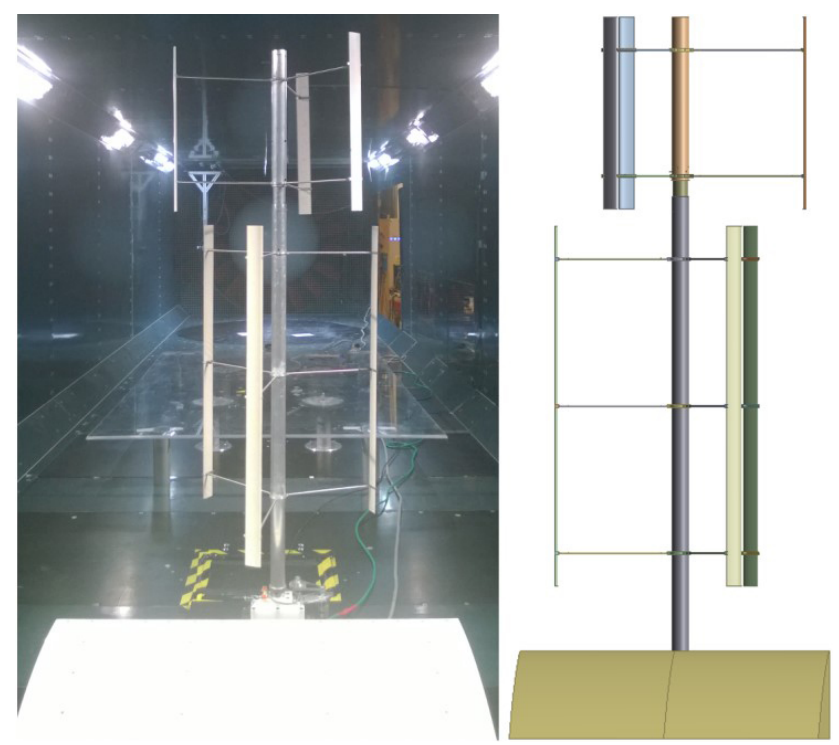

Figure 6. Model set in configuration B.

much smaller than in the single-level configuration $\mathrm{K}$ and also lower than for configuration $\mathrm{A}$, which has no vertical spacing between levels.

\subsection{Configuration C}

Figure 7 displays the model set in configuration C. It shows a dual-level turbine, shifted azimuthally between levels by $60^{\circ}$. The height of the vertical gap between rotor levels is equal to $7.5 \mathrm{~cm}$ - two chord lengths.

Table 4 shows results of measuring bending moments at the bottom of the turbine tower for a range of wind speeds between 4 and $12 \mathrm{~m} / \mathrm{s}$ for a freely rotating wind turbine in configuration C. At the inflow speed of $11 \mathrm{~m} / \mathrm{s}$, the shape of the curve and the fact that both moment amplitudes and peak values are greater than for $12 \mathrm{~m} / \mathrm{s}$ suggest that for $11 \mathrm{~m} / \mathrm{s}$ resonance occurs. The growth of values due to resonance is much smaller than in the single-level configuration $\mathrm{K}$ and also lower than for configuration A or B. The growth of vertical spacing between rotor levels, tested to quantify the effects of decreasing interaction between levels on bending moment values in addition to the azimuthal shift of rotor levels, helps 
Table 2. Case A testing parameters of bending moments for wind speed range.

\begin{tabular}{lrrrrrrrrr}
\hline Wind speed [m/s] & 4 & 5 & 6 & 7 & 8 & 9 & 10 & 11 & 12 \\
\hline Average moment amplitude [Nm] & 0.058 & 0.133 & 0.133 & 0.170 & 0.179 & 0.258 & 0.521 & 1.917 & 0.721 \\
Max moment amplitude [Nm] & 0.098 & 0.199 & 0.235 & 0.262 & 0.336 & 0.508 & 0.898 & 2.132 & 1.390 \\
Min moment amplitude [Nm] & 0.025 & 0.084 & 0.052 & 0.084 & 0.043 & 0.108 & 0.214 & 1.710 & 0.188 \\
Average peak value [Nm] & 0.248 & 0.401 & 0.564 & 0.762 & 0.978 & 1.278 & 1.708 & 2.730 & 2.455 \\
Max peak value [Nm] & 0.278 & 0.441 & 0.612 & 0.833 & 1.145 & 1.394 & 1.922 & 2.893 & 2.854 \\
\hline
\end{tabular}

Table 3. Case B testing parameters of bending moments for wind speed range.

\begin{tabular}{lrrrrrrrrr}
\hline Wind speed [m/s] & 4 & 5 & 6 & 7 & 8 & 9 & 10 & 11 & 12 \\
\hline Average moment amplitude [Nm] & 0.059 & 0.065 & 0.097 & 0.145 & 0.177 & 0.411 & 0.399 & 1.223 & 0.595 \\
Max moment amplitude [Nm] & 0.088 & 0.113 & 0.157 & 0.259 & 0.274 & 0.645 & 0.664 & 1.480 & 0.891 \\
Min moment amplitude [Nm] & 0.025 & 0.022 & 0.030 & 0.043 & 0.066 & 0.185 & 0.164 & 0.895 & 0.128 \\
Average peak value [Nm] & 0.246 & 0.365 & 0.544 & 0.775 & 1.002 & 1.399 & 1.659 & 2.401 & 2.448 \\
Max peak value [Nm] & 0.262 & 0.397 & 0.575 & 0.844 & 1.063 & 1.562 & 1.820 & 2.498 & 2.583 \\
\hline
\end{tabular}

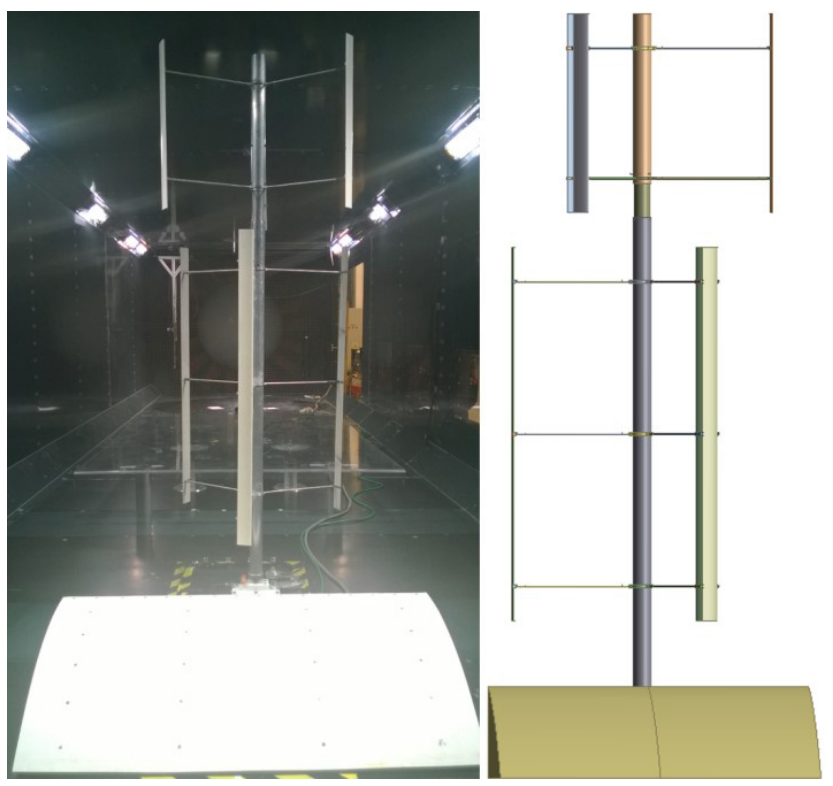

Figure 7. Model set in configuration $\mathrm{C}$.

limit the effects of the sudden moment and moment amplitude growth at certain wind speeds.

\section{Experiment result comparison}

Table 5 shows the reduction of average bending moment amplitude and average peak bending moment value results for each separate inflow speed for every test configuration as compared to configuration K. Except for $4 \mathrm{~m} / \mathrm{s}$, all average bending moment amplitude reduction levels for configuration B are greater than for configuration A. Configuration C shows superior average bending moment amplitude reduc- tion levels to configuration B for $7 \mathrm{~m} / \mathrm{s}$ and the range of 9$12 \mathrm{~m} / \mathrm{s}$. The vertical spacing between levels also increases the height of the structure as well as moves the model further from optimal level-length proportions, which were optimized for configuration $\mathrm{A}$. The results show that growth of vertical spacing corresponded to a drop in average peak bending moment value reduction for inflow speeds of below $10 \mathrm{~m} / \mathrm{s}$, at which point resonance begins to influence test results.

For results presented in this paper, there can be several ways of assessing the average reduction in bending moment and bending moment amplitude values. The simplest way would be to take reduction percentage values from Table 5 and make a simple average of them. For purposes relating to product lifetime, a more realistic approach would be to take an average but discard the values at low inflow speeds - too small to influence turbine lifetime, as compared to values at higher inflow speeds. For a range of relevant wind speeds set from 8 to $12 \mathrm{~m} / \mathrm{s}$, an average reduction of bending moment amplitude in configuration $\mathrm{A}$ was at $67 \%$, while the average reduction of peak bending moment values was at $32 \%$. For configuration $\mathrm{B}$, the reductions calculated thusly were likewise $71 \%$ and $33 \%$; for configuration $\mathrm{C}$ they were $72 \%$ and $31 \%$. Another simple approach would be to make an unweighted sum of all measured mean values for every configuration and quantify the reduction between those sums. A modification of this approach is weighing the results at all tested wind speeds, by probability of their occurrence. This has been done using the Weibull wind speed distribution curve for reasonable European wind farm siting conditions - a middle-of-rotor average wind speed of $5.7 \mathrm{~m} / \mathrm{s}$ and $k$ shape factor equal to 2.1 (Kiss and Jánosi, 2008). For this averaging method, moment amplitudes in configuration A were limited on average by $80 \%$, while the average reduction of peak bending moment values at the tower base was $42 \%$, as compared to configuration K. For configuration B, the reduc- 
Table 4. Case $\mathrm{C}$ testing parameters of bending moments for wind speed range.

\begin{tabular}{lrrrrrrrrr}
\hline Wind speed [m/s] & 4 & 5 & 6 & 7 & 8 & 9 & 10 & 11 & 12 \\
\hline Average moment amplitude [Nm] & 0.063 & 0.090 & 0.147 & 0.136 & 0.249 & 0.290 & 0.393 & 0.940 & 0.580 \\
Max moment amplitude [Nm] & 0.111 & 0.149 & 0.209 & 0.217 & 0.441 & 0.520 & 0.766 & 1.264 & 1.122 \\
Min moment amplitude [Nm] & 0.029 & 0.055 & 0.072 & 0.059 & 0.077 & 0.035 & 0.100 & 0.630 & 0.144 \\
Average peak value [Nm] & 0.261 & 0.407 & 0.594 & 0.797 & 1.087 & 1.399 & 1.723 & 2.340 & 2.529 \\
Max peak value [Nm] & 0.287 & 0.448 & 0.643 & 0.864 & 1.159 & 1.564 & 1.946 & 2.490 & 2.776 \\
\hline
\end{tabular}

Table 5. Result comparison for different scenarios.

\begin{tabular}{lrrrr|rrrr}
\hline Inflow velocity [m/s] & \multicolumn{3}{c|}{$\begin{array}{c}\text { Average bending moment } \\
\text { amplitude reduction }\end{array}$} & \multicolumn{4}{c}{$\begin{array}{c}\text { Average peak moment } \\
\text { value reduction }\end{array}$} \\
\cline { 2 - 9 } & $\mathrm{K}$ & $\mathrm{A}$ & $\mathrm{B}$ & $\mathrm{C}$ & $\mathrm{K}$ & $\mathrm{A}$ & $\mathrm{B}$ & $\mathrm{C}$ \\
\hline 4 & $0 \%$ & $25 \%$ & $23 \%$ & $18 \%$ & $0 \%$ & $3 \%$ & $3 \%$ & $-2 \%$ \\
5 & $0 \%$ & $-31 \%$ & $37 \%$ & $12 \%$ & $0 \%$ & $3 \%$ & $12 \%$ & $1 \%$ \\
6 & $0 \%$ & $45 \%$ & $60 \%$ & $40 \%$ & $0 \%$ & $12 \%$ & $15 \%$ & $8 \%$ \\
7 & $0 \%$ & $53 \%$ & $59 \%$ & $62 \%$ & $0 \%$ & $14 \%$ & $12 \%$ & $10 \%$ \\
8 & $0 \%$ & $66 \%$ & $66 \%$ & $52 \%$ & $0 \%$ & $20 \%$ & $18 \%$ & $11 \%$ \\
9 & $0 \%$ & $78 \%$ & $66 \%$ & $76 \%$ & $0 \%$ & $30 \%$ & $23 \%$ & $23 \%$ \\
10 & $0 \%$ & $93 \%$ & $95 \%$ & $95 \%$ & $0 \%$ & $70 \%$ & $71 \%$ & $69 \%$ \\
11 & $0 \%$ & $42 \%$ & $63 \%$ & $72 \%$ & $0 \%$ & $22 \%$ & $32 \%$ & $33 \%$ \\
12 & $0 \%$ & $57 \%$ & $64 \%$ & $65 \%$ & $0 \%$ & $19 \%$ & $20 \%$ & $17 \%$ \\
\hline
\end{tabular}

tions were likewise $82 \%$ and $42 \%$; for configuration $\mathrm{C}$ they were $84 \%$ and $40 \%$.

\section{CFD validation}

A validation of the load-limiting concept on industrial scale has been performed using 3D CFD in ANSYS Fluent. Compared was a dual-level straight-bladed wind turbine with the vertical spacing between levels equal to one blade chord length, based on experimental configuration $\mathrm{B}-1.5 \mathrm{~m}$ and a single-level straight-bladed turbine with identical chord, rotor length and diameter.

Figure 8 shows a side view of the geometry used for the computational domain for the dual-level scenario. For both scenarios the blade chord, total rotor length and diameter are exactly 40 times that of the experimental cases. The blades were set $3^{\circ}$ to the outside of the rotor, relative to the blades' motion path. This parameter and others such as the chord-todiameter ratio were chosen as a result of 2D CFD production optimization. The airfoil used, after testing the influence of airfoil thickness for a range of angles of blade attachment with 2D simulations, was once again NACA0018.

Figure 9 displays a bottom side view of the mesh for the entire domain as well as the sweepable mesh on one of the blades. The trailing edge was divided into two parts, the rest of the blade into 550 parts. Automatic boundary layer creation - as incompatible with the sweep method used - was not implemented. The simulation was conducted with the $\mathrm{k}-\omega$ shear stress transport (SST) turbulence method, default

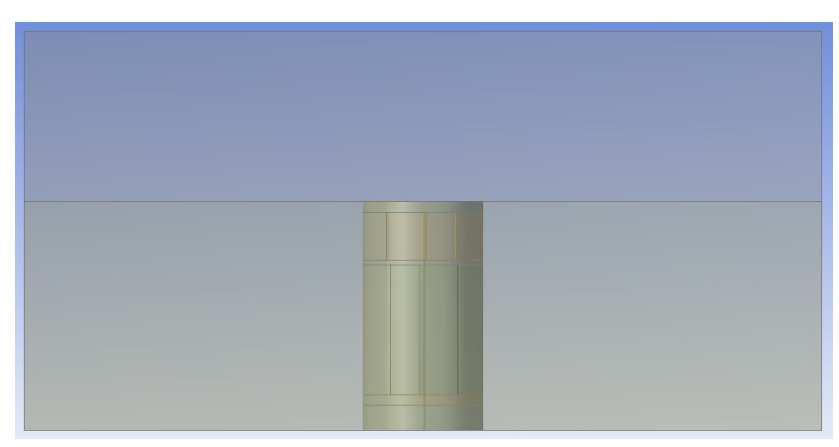

Figure 8. Computational domain geometry for dual-level scenario.

turbulence parameters and surface roughness, a $9 \mathrm{~m} / \mathrm{s}$ inflow speed, a rotational speed of 140 degree/s and $0.01 \mathrm{~s}$ time step.

Figure 10 shows the $Y$-bending moments, according to Fluent's default coordinate system, at the bottom of the rotor shaft, analogous to the moments measured during the experimental comparison in the first part of the paper. Compared to the single-level scenario, in the dual-level scenario the maximum $Y$-moment values within a cycle are limited by $19.7 \%$, while the $Y$-moment amplitude is limited by $87.5 \%$.

Figure 11 shows the $X$-bending moments at the bottom of the rotor shaft, generated due to lift. Compared to the singlelevel scenario, in the dual-level scenario the maximum positive $X$-moment values within a cycle are limited by $97.5 \%$ and the maximum negative $X$-moment values within a cycle are limited by $73.6 \%$, while the $X$-moment amplitude 


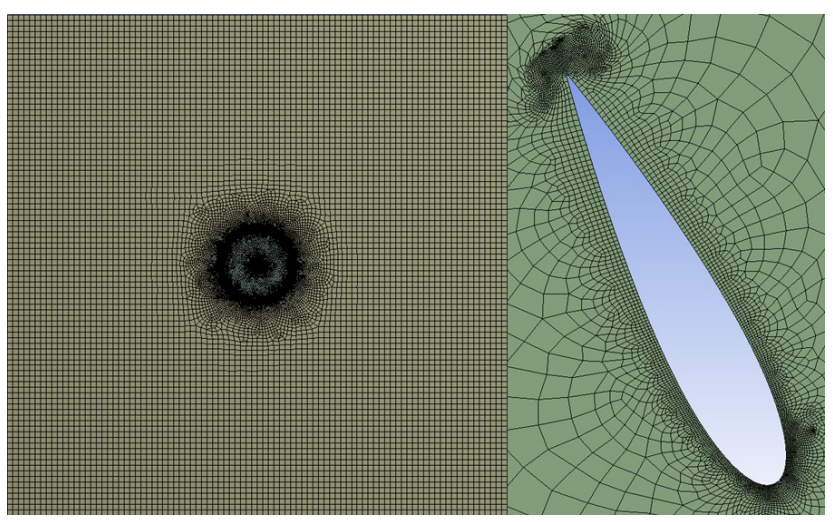

Figure 9. Bottom side view of select mesh parts.

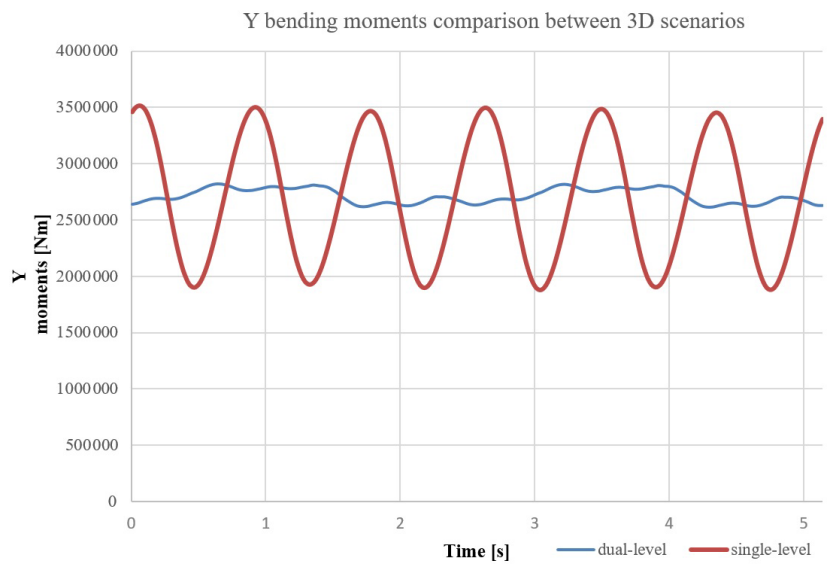

Figure 10. $Y$-bending moments comparison between 3D scenarios.

is limited by $83.6 \%$. Finally, in the dual-level scenario, the maximum total moments at the bottom of the rotor shaft are limited by $20.6 \%$, while the total moment amplitude is limited by $87.4 \%$.

\section{Conclusions}

In the laboratory-scale model the lift-based bending moment component at the bottom of the turbine shaft became lost and unmeasurable among the measurement noise and a very unfavorable lift-to-drag ratio of the NACA0018 airfoil at low Reynolds numbers. Within the simulations, the 2.4 million to 4 million Reynolds numbers were much more advantageous in terms of airfoil lift-to-drag ratios, resulting in a lift component taking a more distinct role in total bending moment values at the bottom of the rotor shaft. The influence of the lift-based component on total moments is much lower than the $Y$ component even in the large-scale simulation, resulting in a small increase of maximum total moment value limiting and a slight decrease in limiting the total amplitude within a cycle. Both the experimental testing and large-scale CFD validation offered very high levels of reduction of bending

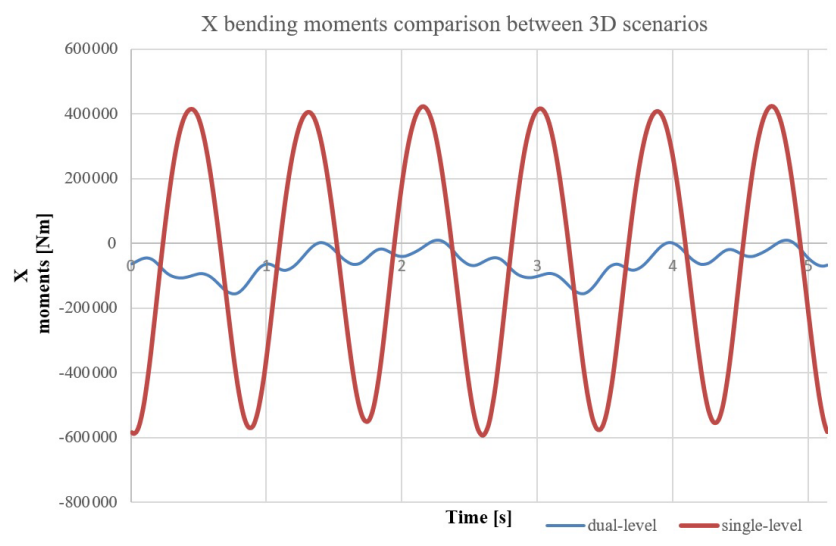

Figure 11. $X$-bending moments comparison between 3D scenarios.

moments at the bottom of the turbine shaft, proportional to cyclic loading values. The obtained results, along with prior tests, yield a high probability of the concept being applicable in creating reliable, sleeker and more cost-efficient designs than previously exploited. Further validating those assumptions with mid-scale environmental testing and a mechanical analysis of all relevant turbine elements is planned as the next research step within the topic.

Data availability. The data are not publicly accessible as a part of the technology know-how is property of Vertical Axis Wind Technologies LLC.

Author contributions. JW was responsible for concept creation, authorship of basic methodology, experiments and simulation. KR helped with article writing and methodology validation. KG set up the experiment and helped with the experiment methodology, data acquisition and problem solving. JS was responsible for the methodology aid and validation, as well as quality control.

Competing interests. Author Jan Wiśniewski has filed for IP protection of solutions related to the presented concept prior to conducting validation presented in the article and has shared ownership within a wind-industry-related company - Vertical Axis Wind Technologies LLC.

Special issue statement. This article is part of the special issue "Wind Energy Science Conference 2019". It is a result of the Wind Energy Science Conference 2019, Cork, Ireland, 17-20 June 2019.

Acknowledgements. We acknowledge members of the WUT Division of Aerodynamics, for their constant insight and helpfulness. 
Review statement. This paper was edited by Raúl Bayoán Cal and reviewed by Peter Jamieson and one anonymous referee.

\section{References}

Ahmadi-Baloutaki, M., Carriveau, R., and Ting, D. S.-K.: Straight-bladed vertical axis wind turbine rotor design guide based on aerodynamic performance and loading analysis, Journal of Power and Energy, 228, 742, https://doi.org/10.1177/0957650914538631, 2014.

Chinchilla, R., Guccione, S., and Tillman, J.: Wind Power Technologies: A Need for Researchand Development in Improving VAWT's Airfoil Characteristics, J. Indust. Technol., 27, 1-13, https://doi.org/10.1155/2018/8350243, 2011.

Galinos, C., Larsen, T., Aagaard Madsen, H., and Schmidt Paulsen, U.: Vertical Axis Wind Turbine Design Load Cases Investigation and Comparison with Horizontal Axis Wind Turbine, Energy Procedia, 94, 319-328, https://doi.org/10.1016/j.egypro.2016.09.190, 2016.

Guo, J., Liu, L., Lv, X., and Tang, Y.: The Aerodynamic Analysis of Helical-Type VAWT With Semi Empirical and CFD Method, proceedings of the International Conference on Ocean, Offshore, and Arctic Engineering, OMAE2019-95207, V010T09A046, https://doi.org/10.1115/OMAE2019-95207, 2019

Iida, A., Mizuno, A., and Fukudome, K.: Numerical Simulation of Aerodynamic Noise Radiated form Vertical Axis Wind Turbines, Proceedings of the 18th International Congress on Acoustics, Kyoto, Japan, 2004.

Islam, M., Fartaj, J., and Carriveau, R.: Analysis of the Design Parameters Related to a Fixed-Pitch Straight-Bladed Vertical 240 Axis Wind Turbine, Wind Engineering, 32, 491-507, https://doi.org/10.1260/030952408786411903, 2008.
Kiss, P. and Janosi, I. M.: Comprehensive empirical analysis of ERA-40 surface wind speed distribution over Europe, Energ. Convers. Manag., 49, 2142-2151, https://doi.org/10.1016/j.enconman.2008.02.003, 2008.

Laneville, A. and Vittecoq, P.: Dynamic Stall: The Case of the Vertical Axis Wind Turbine, J. Sol. Energy Eng., 108, 140-145, https://doi.org/10.1115/1.3268081, 1986.

Marini, M., Gazzano, R., and Satta, A.: Semi-Empirical Methods for the Analysis of Vertical Axis Wind Turbines With Helical Blades, ASME Turbo Expo 2010: Power for Land, Sea, and Air conference paper, https://doi.org/10.1115/GT2010-23460, 2010.

Oerlemans, S. and Migliore, P.: Aeroacoustic Wind Tunnel Tests of Wind Turbine Airfoils, 10th AIAA/CEAS Aeroacoustics Conference, 10-12 May 2004, Manchester, Great Britain, https://doi.org/10.2514/6.2004-3042, 2004.

Parashivoiu, I.: Wind Turbine Design: With Emphasis on Darrieus Concept, PIP, 438 pp., ISBN-10 2553009313, ISBN-13 9782553009310, 2002.

Rogowski, K., Hansen, M., and Maroński, R.: Steady and unsteady analysis of NACA 0018 airfoil in vertical-axis wind turbine, J Theor. Appl. Mech., 56, 203-212, https://doi.org/10.15632/jtampl.56.1.203, 2018.

Scheurich, F., Fletcher, T. M., and Brown, R. E.: Effect of blade geometry on the aerodynamic loadsproduced by vertical-axis wind turbines, Proceedings of the Institution of Mechanical Engineers, Part A: Journal of Power and Energy, 225, 327-341, https://doi.org/10.1177/2041296710394248, 2011.

Simão Ferreira, C., Aagaard Madsen, H., Barone, M., Roscher, B., Deglaire, P., and Arduin, I.: Comparison of aerodynamic models for Vertical Axis Wind Turbines, Journal of Physics: Conference Series, 524, 012125, https://doi.org/10.1088/17426596/524/1/012125, 2014. 